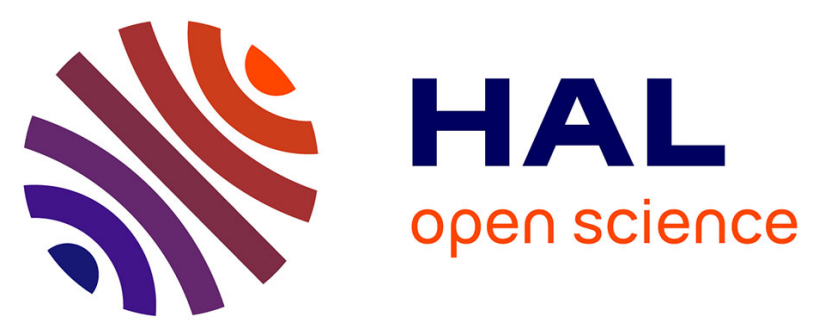

\title{
Controlling photophysics of styrylnaphthalimides through TICT, fluorescence and E,Z-photoisomerization interplay
}

Pavel A. Panchenko, Antonina N. Arkhipov, Olga A. Fedorov, Yuri V. Fedorov, Marina A. Zakharko, Dmitry E. Arkhipov, Gediminas Jonusauskas

\section{To cite this version:}

Pavel A. Panchenko, Antonina N. Arkhipov, Olga A. Fedorov, Yuri V. Fedorov, Marina A. Zakharko, et al.. Controlling photophysics of styrylnaphthalimides through TICT, fluorescence and E,Z-photoisomerization interplay. Physical Chemistry Chemical Physics, 2017, 19 (2), pp.1244 1256. 10.1039/C6CP07255K . hal-01477676

\section{HAL Id: hal-01477676 https://hal.science/hal-01477676}

Submitted on 27 Feb 2017

HAL is a multi-disciplinary open access archive for the deposit and dissemination of scientific research documents, whether they are published or not. The documents may come from teaching and research institutions in France or abroad, or from public or private research centers.
L'archive ouverte pluridisciplinaire HAL, est destinée au dépôt et à la diffusion de documents scientifiques de niveau recherche, publiés ou non, émanant des établissements d'enseignement et de recherche français ou étrangers, des laboratoires publics ou privés.

\section{다(1)(2)}

Distributed under a Creative Commons Attribution - ShareAlikel 4.0 International 


\title{
Controlling photophysics of styrylnaphthalimides through TICT, fluorescence and $E, Z$-photoisomerization interplay $\dagger$
}

\author{
Pavel A. Panchenko, ${ }^{a b}$ Antonina N. Arkhipova, ${ }^{a}$ Olga A. Fedorova, ${ }^{a b}$ \\ Yuri V. Fedorov, ${ }^{a}$ Marina A. Zakharko, ${ }^{a}$ Dmitry E. Arkhipov ${ }^{a}$ and \\ Gediminas Jonusauskas ${ }^{\mathrm{A}}$
}

\begin{abstract}
The photophysical properties of naphthalimide dyes NI1-3 with electron releasing 4-methoxy- (NI1), 3,4-dimethoxystyryl- (NI2) and dimethylaminostyryl (NI3) groups are examined in a variety of protic and aprotic solvents. All compounds demonstrate positive solvatochromism in the steady-state absorption and fluorescence spectra. The analysis of the dependence of the Stokes shift on the polarity of the solvent using the Lippert Mataga equation allowed us to determine the change in the dipole moment upon excitation. The obtained data correspond to the formation of highly polar charge transfer states. Based on the transient absorption spectra and time-resolved fluorescence measurements, the presence of two different emissive states was definitely proved. The primarily formed planar Local Excited (LE) state dominates in non-polar solvents like cyclohexane and toluene where it relaxes mostly through fluorescence and E,Z-isomerisation pathways. In polar solvents, an alternative relaxation channel emerges that consists of twisting around single bond between styryl and naphthalimide fragments, which leads to the formation of a Twisted Intramolecular Charge Transfer (TICT) state. The factors affecting the fluorescence of TICT states are discussed. The observed spectral effects are rationalized using quantum-chemical calculations, X-ray data and NMR spectroscopy.
\end{abstract}

\section{Introduction}

Molecular fluorescence is presently regarded as a dominant methodology used extensively in biotechnology, flow cytometry, medical diagnostics, DNA sequencing and genetic analysis. ${ }^{1}$ The recent development of confocal fluorescent microscopy ${ }^{2,3}$ has greatly advanced the application of organic emissive compounds as imaging agents to study the structure, dynamics and functions of biological macromolecules. The operational light input/output wavelengths of most current fluorescent indicators are in the range of 400-600 $\mathrm{nm}$, which often limits their use in life sciences, because this spectral region suffers from strong interference due to background absorbance and auto-fluorescence from the

\footnotetext{
${ }^{a}$ A. N. Nesmeyanov Institute of Organoelement Compounds of Russian Academy of Sciences (INEOS RAS), Vavilova str. 28, Moscow, 119991, Russia. E mail: pavel@ineos.ac.ru; Fax: +7 49913550 85; Tel: +7 4991358098

${ }^{b}$ D. Mendeleev University of Chemical Technology of Russia, Miusskaya sqr. 9, Moscow, 125047, Russia

${ }^{c}$ Laboratoire Ondes et Matière d'Aquitaine (LOMA), UMR CNRS 5798, Bordeaux University, 351 Cours de la Libération, Talence, 33405, France † Electronic supplementary information (ESI) available. CCDC 10371661037168. For ESI and crystallographic data in CIF or other electronic format see DOI: $10.1039 / \mathrm{c} 6 \mathrm{cp} 07255 \mathrm{k}$
}

biological environment or endogenous chromophores in sample media. So, it has attracted much attention to develop new nearinfrared fluorescent dyes as powerful detecting or treating tools in biological systems. ${ }^{4-6}$

Many researchers have used cyanine dyes as fluorescent labels or sensors for biomolecules in vivo, because their spectra can reach the near-infrared (NIR) region. ${ }^{7-9}$ However, polymethine cyanine dyes are not so easy to be synthesized and modified, their photo-stabilities are relatively low and their Stokes shift is usually less than $25 \mathrm{~nm}$, which may cause selfquenching and measurement error by the excited and scattered light, and then decrease the detection sensitivity to a great extent. Therefore, NIR dyes with a larger Stokes shift are very promising for NIR fluorescence bioassays.

1,8-Naphthalimide derivatives are famous organic fluorophores which generally exhibit high thermo- and photostability and are known to act as fluorescent brighteners and dyes for polymer fibers, ${ }^{10,11}$ laser active media, ${ }^{12,13}$ electroluminescent materials ${ }^{14-16}$ and optical memory devices. ${ }^{17-19}$ Because of their intense fluorescence, large Stokes shifts along with the relative ease of synthetic operations for targeted modification of the molecular structure, these types of compounds have found application in the construction of fluorescent chemosensors 

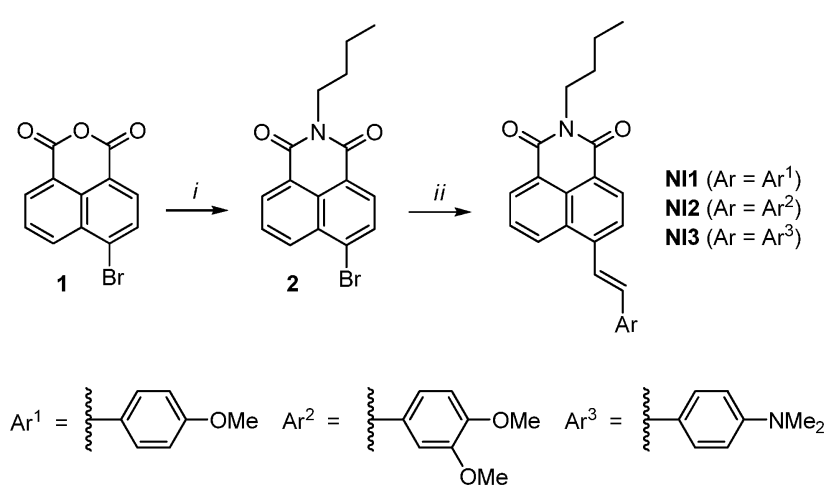

Scheme 1 Synthetic route to compounds NI1-3. Reagents, conditions and yields: (i) $n \mathrm{BuNH}_{2}$, $\mathrm{EtOH}, 4,89 \%$; (ii) $\mathrm{Ar} \mathrm{CH} \mathrm{CH}_{2}$, (o Tol) $)_{3} \mathrm{P}, \mathrm{Pd}(\mathrm{OAC})_{2}$, DMF, $\Delta, 18 \quad 38 \%$.

for biologically relevant cations and anions, ${ }^{20-22}$ labels or probes for proteins, cells, lysosomes and other acidic organelles. ${ }^{23-25}$ However, the emission bands of most naphthalimides are in blue and green-yellow regions, which is a characteristic of 4-amino-, 4-amido- and 4-alkoxy-substituted derivatives. ${ }^{26-28}$ Although it was known that electron-donating groups at the $C$-4,5-positions of the naphthalene ring usually increase the fluorescence quantum yield of the compounds and cause the red shift in the spectra, the reports on 1,8-naphthalimide derivatives with emission wavelengths longer than $600 \mathrm{~nm}$ are very few. ${ }^{29-33}$

In the present work we focused on the synthesis and detailed spectroscopic investigation of naphthalimides NI1-3 (Scheme 1) with $\mathrm{NMe}_{2}$ and OMe groups attached to the styryl fragment. It is known that compounds with a structure similar to NI1-3 are capable of penetrating cell membranes, demonstrate AIE properties and have great potential of being used as imaging agents in vivo, ${ }^{32,33}$ even so, their optical properties have been explored to a much lesser extent as compared to commonly used 4-amino- and 4-alkoxynaphthalimides. The presence of the styryl group in NI1-3 is supposed to extend the conjugation system of the parent chromophore and thus, provide the longer wavelength position of fluorescence maxima. At the same time, as a key feature of styryl dyes, ${ }^{34-36}$ one should expect a significant impact of twisted intramolecular charge-transfer (TICT) state formation and photoisomerization around double bonds on the photophysics of the compounds under study. The effects of the molecular structure of the styryl fragment as well as the solvent polarity on the steady-state and time-resolved optical characteristics are described and discussed below.

\section{Experimental section}

\section{General procedure for the synthesis of compounds NI1-3}

Synthesis of the naphthalimide derivatives NI1-3 is shown in Scheme 1. The first step, in which commercial starting material 4-bromo-1,8-naphthalic anhydride 1 reacted with $n$-butylamine, was performed conveniently in ethanol at reflux. Next, the samples of 2 were subjected to the Heck coupling reaction with 4-methoxystyrene, 3,4-dimethoxystyrene and 4- $\mathrm{N}, \mathrm{N}$-dimethylaminostyrene in the presence of catalyst $\mathrm{Pd}(\mathrm{OAc})_{2} \cdot{ }^{32}$ The details of synthetic procedures and identifications are shown in the ESI. $\dagger$

\section{Steady-state optical measurements}

The absorption spectra were taken on a Varian-Cary 5G spectrophotometer. The fluorescence quantum yield measurements were performed using a Varian-Cary 5G spectrophotometer and a FluoroMax-3 spectrofluorimeter. Spectral measurements were carried out in air-saturated acetonitrile solutions (acetonitrile of spectrophotometric grade, water content $<0.005 \%$, Aldrich) at $20 \pm 1{ }^{\circ} \mathrm{C}$; the concentrations of the studied compounds were about $0.5-2.0 \times 10^{-5} \mathrm{M}$. All measured fluorescence spectra were corrected for the nonuniformity of detector spectral sensitivity. Coumarin 481 in acetonitrile $\left(\varphi^{\mathrm{fl}}=0.08\right)^{37}$ was used as a reference for the fluorescence quantum yield measurements. The fluorescence quantum yields were calculated using eqn (1): ${ }^{38}$

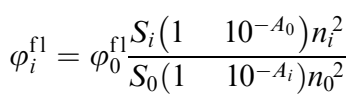

wherein $\varphi_{i}^{\mathrm{fl}}$ and $\varphi_{0}^{\mathrm{fl}}$ are the fluorescence quantum yields of the studied solution and the standard compound, respectively; $A_{i}$ and $A_{0}$ are the absorptions of the studied solution and the standard, respectively; $S_{i}$ and $S_{0}$ are the areas underneath the curves of the fluorescence spectra of the studied solution and the standard, respectively; $n_{i}$ and $n_{0}$ are the refraction indices of the solvents for the substance under study and the standard compound.

\section{Time-resolved fluorescence setup}

A Ti:sapphire laser system emitting pulses of $0.6 \mathrm{~mJ}$ and $30 \mathrm{fs}$ at $800 \mathrm{~nm}$ and $1 \mathrm{kHz}$ pulse repetition rate (Femtopower Compact Pro) with a home-built optical parametric generator and frequency mixers was used to excite the samples at the maximum of the steady-state absorption band. All excited-state lifetimes were obtained by using depolarized excitation light. The highest pulse energies used to excite fluorescence did not exceed $100 \mathrm{~nJ}$ and the average power of the excitation beam was $0.1 \mathrm{~mW}$ at a pulse repetition rate of $1 \mathrm{kHz}$ focused into a spot with a diameter of $0.1 \mathrm{~mm}$ in the $10 \mathrm{~mm}$-long fused-silica cell. The fluorescence emitted in the forward direction was collected by reflective optics and focused with a spherical mirror onto the input slit of a spectrograph (Chromex 250) coupled to a streak camera (Hamamatsu 5680 equipped with a fast single sweep unit M5676, temporal resolution $2 \mathrm{ps}$ ). Convolution of a rectangular streak camera slit in the sweep range of $250 \mathrm{ps}$ with an electronic jitter of the streak camera trigger pulse provided a Gaussian (over four decades) temporal apparatus function with a full width at half-maximum of 20 ps. The fluorescence kinetics were later fitted by means of the Levenberg-Marquardt least-squares curve-fitting method using a solution of the differential equation describing the evolution in time of a single excited state and neglecting the depopulation of the ground state according to eqn (2):

$$
\frac{\mathrm{d} I}{\mathrm{~d} t}=\operatorname{Gauss}\left(t_{0}, \Delta t, A\right) \quad \frac{I(t)}{\tau}
$$


where $I(t)$ is the fluorescence intensity, and Gauss is the Gaussian profile of the excitation pulse, in which $t_{0}$ is the excitation pulse arrival delay, $\Delta t$ - the excitation pulse width, and $A$ - the amplitude. The parameter $\tau$ is the lifetime of the excited state. The initial condition for the equation is $I(\infty)=0$. Typically, the fit shows a $\chi^{2}$ value (Pearson's criteria) better than $10^{-4}$ and a correlation coefficient $R>0.999$. The uncertainty of the lifetime was better than $1 \%$. Routinely, the fluorescence accumulation time in our measurements did not exceed $90 \mathrm{~s}$.

\section{Transient absorption setup}

The laser system and frequency-conversion apparatus employed to excite samples were the same as for time-resolved fluorescence measurements. White light continuum (360-1000 nm) pulses generated in a $5 \mathrm{~mm}$ methanol cell were used as a probe. The variable delay time between excitation and probe pulses was obtained by using a delay line with $0.1 \mathrm{~mm}$ resolution. The solutions were placed in a $1 \mathrm{~mm}$ circulating cell. White light signals and reference spectra were recorded using a two-channel fiber spectrometer (Avantes Avaspec-2048-2). A home-written acquisition and experiment-control program in LabView made it possible to record transient spectra with an average error of less than $10^{-4}$ times the optical density for all wavelengths. The temporal resolution of our setup was better than 60 fs. The temporal chirp of the probe pulse was corrected using a computer program with respect to a Lawrencian fit of a Kerr signal generated in a $0.2 \mathrm{~mm}$ glass plate used in the place of the sample.

\section{Determination of $E, Z$-photoisomerization quantum yields}

To determine the quantum yields of the forward and backward reactions of $E$,Z-photoisomerization $\left(\varphi^{E \rightarrow Z}\right.$ and $\left.\varphi^{Z \rightarrow E}\right)$ of compounds NI1-3, we carried out the preliminary calculation of the absorption spectra of the corresponding $Z$-isomers and the ratios of quantum yields $\varphi^{E \rightarrow Z} / \varphi^{Z \rightarrow E}$ using the Fisher $\operatorname{method}^{39}$ from the absorption spectra of the $E$-isomers and the spectra of two photostationary states obtained by photoirradiation at two different wavelengths. As a light source a DRK 120 mercury lamp $(120 \mathrm{~W})$ was used. Particular spectral lines of this lamp were picked out using glass light filters from the standard set of samples of colored optical glasses. The changes in the absorption spectra upon irradiation and the spectra of $Z$-isomers are presented in the ESI $\dagger$ (Fig. S1-S9).

The quantum yields $\varphi^{E \rightarrow Z}$ and $\varphi^{Z \rightarrow E}$ were calculated as follows. For the reversible photochemical reaction ${ }^{40}$

$$
\mathrm{A} \stackrel{h \nu}{\rightleftharpoons} \mathrm{B}
$$

the equations for the rate of formation of substances A and $\mathrm{B}$ are written in the form

$$
\begin{aligned}
& \frac{\mathrm{d}[\mathrm{A}]}{\mathrm{d} \tau}=\varphi^{\mathrm{A} \rightarrow \mathrm{B}} \cdot I_{\mathrm{abs}}^{\mathrm{A}}+\varphi^{\mathrm{B} \rightarrow \mathrm{A}} \cdot I_{\mathrm{abs}}^{\mathrm{B}} \\
& \frac{\mathrm{d}[\mathrm{B}]}{\mathrm{d} \tau}=+\varphi^{\mathrm{A} \rightarrow \mathrm{B}} \cdot I_{\mathrm{abs}}^{\mathrm{A}} \quad \varphi^{\mathrm{B} \rightarrow \mathrm{A}} \cdot I_{\mathrm{abs}}^{\mathrm{B}}
\end{aligned}
$$

where $I_{\mathrm{abs}}^{\mathrm{A}}$ and $I_{\mathrm{abs}}^{\mathrm{B}}$ are the amounts of radiation quanta absorbed by substances $\mathrm{A}$ and $\mathrm{B}$ within time $\mathrm{d} \tau$; and $\varphi^{\mathrm{A} \rightarrow \mathrm{B}}$ and $\varphi^{\mathrm{B} \rightarrow \mathrm{A}}$ are the quantum yields of the forward and backward reaction, respectively; $\mathrm{d}[\mathrm{A}]$ and $\mathrm{d}[\mathrm{B}]$ are the changes in the number of molecules of the corresponding substances A and B within time $\mathrm{d} \tau$.

The amount of quanta absorbed by substances A and B is determined as follows:

$$
\begin{aligned}
& I_{\mathrm{abs}}^{\mathrm{A}}=I_{\mathrm{abs}}^{\Sigma} \cdot \frac{D_{\mathrm{A}}}{D_{\Sigma}} \\
& I_{\mathrm{abs}}^{\mathrm{B}}=I_{\mathrm{abs}}^{\Sigma} \cdot \frac{D_{\mathrm{B}}}{D_{\Sigma}}
\end{aligned}
$$

in this case

$$
I_{\mathrm{abs}}^{\Sigma}=I_{0}\left(1-10^{-D_{\Sigma}}\right)
$$

where $D_{\Sigma}$ is the total absorption of all components, $D_{\mathrm{A}}$ and $D_{\mathrm{B}}$ are the absorption by the corresponding substance, $I_{\mathrm{abs}}^{\Sigma}$ is the total amount of absorbed radiation quanta within time $\mathrm{d} \tau$, and $I_{0}$ is the incident radiation intensity.

The quantum yields $\varphi^{\mathrm{A} \rightarrow \mathrm{B}}$ and $\varphi^{\mathrm{B} \rightarrow \mathrm{A}}$ were determined using the numerical solution of the corresponding differential equations using the primarily specified value and the ratio of quantum yields of the forward and backward reactions preliminarily measured using the Fisher method. The quantum yield values were optimized by the iteration method using the program in the Visual Basic language incorporated into Microsoft Excel.

The absolute light intensity $I_{0}$ was measured using a ferrioxalate actinometer ${ }^{41,42}$ before each photolysis experiment (for details also see the ESI $\dagger$ ). The measurement accuracy does not exceed $20 \%$.

\section{X-ray diffraction analysis}

The crystals suitable for X-ray analysis were prepared by slow evaporation of solutions of compounds NI1-3 in solvent mixtures benzene-dichloromethane $(\mathrm{v} / \mathrm{v}=1: 1)$, ethanol-ethyl acetate $(\mathrm{v} / \mathrm{v}=1: 1)$ and DMF, respectively. The measurements were carried out using a SMART APEX II CCD diffractometer (MoK $\alpha$ irradiation, graphite monochromator, $\omega$-scanning). The structures were solved by the direct method and refined by the full-matrix leastsquares technique against $F_{h k l}^{2}$ in the anisotropic approximation. Hydrogen atoms were placed in calculated positions and refined in the riding model using isotropic approximation. The main crystallographic parameters can be found in the ESI $\dagger$ (Table S1). All calculations were performed using SHELX software package. ${ }^{43}$ The X-ray data of NI1-3 have been deposited with the Cambridge Crystallographic Data Centre as supplemental publications CCDC 1037166-1037168.

\section{Computational details}

Quantum chemical calculations were carried out by the MOPAC 2012 program package using the PM6 semiempirical method. ${ }^{44}$ CI calculations were performed at optimized geometries, which reached gradient variations less than $0.01 \mathrm{kcal} \mathrm{mol}^{-1}$. The solvent effect was included in geometry optimizations following 
the "COnductorlike Screening Model" (COSMO) implemented in MOPAC 2012. A dielectric constant of $\varepsilon=20$ and a refraction index of solvent $(n)$ such that $n^{2}=2$ were used for geometry optimization and calculations of electron distribution of the HOMO and the LUMO in compounds NI1-3. The CI included eight occupied and eight unoccupied MOs.

\section{NMR measurements}

${ }^{1} \mathrm{H}$ NMR spectra were recorded on an Avance 600 spectrometer (Bruker) operating at $600.22 \mathrm{MHz}$. The measurements were performed in toluene- $d_{8}$ solution at room temperature. The chemical shifts (given as $\delta$ ) were determined with an accuracy of $0.01 \mathrm{ppm}$ relative to the signals corresponding to the residual solvent and recalculated to the internal standard (TMS); the spin-spin coupling constants $(J)$ were measured with an accuracy of $0.1 \mathrm{~Hz}$. The numbering of carbon atoms in the naphthalimide moiety, the $N$-butyl group and the styryl fragment of compounds NI1-3 used for the description of ${ }^{1} \mathrm{H}$ NMR spectra is shown in Fig. 6. The signals of $Z$-isomers were identified using the preliminary recorded spectra of $E$-isomers and the spectra of photostationary states collected after $20 \mathrm{~min}$ of irradiation of toluene- $d_{8}$ solutions of NI1-3 using a $436 \mathrm{~nm}$ light (DRK 120 mercury lamp, $120 \mathrm{~W}$ ). The assignment of signals is based on 2D NMR experiments (HMBC, HSQC and ${ }^{1} \mathrm{H}$ COSY), which were performed using standard pulse sequences from the Bruker library. 2D NMR spectra are presented in the ESI $\dagger$ (Fig. S11-S28).

(E)-2-Butyl-6-(4-methoxystyryl)-1H-benzo[d,e]isoquinoline1,3(2H)-dione (E-NI1). ${ }^{1} \mathrm{H}$ NMR: $0.92\left(\mathrm{t}, 3 \mathrm{H}, \mathrm{CH}_{3}(1), J=7.3\right)$, 1.35-1.43 (m, 2H, $\left.\mathrm{CH}_{2}(2)\right)$, 1.75-1.83 (m, 2H, $\left.\mathrm{CH}_{2}(3)\right), 3.33$ $\left(\mathrm{s}, 3 \mathrm{H}, \mathrm{OCH}_{3}\right), 4.25$ (t, 2H, $\left.\mathrm{CH}_{2}(4), J=7.9\right), 6.80(\mathrm{~d}, 2 \mathrm{H}, \mathrm{H}(21)$, $\mathrm{H}(23), J=8.7), 6.98$ (d, 1H, H(18), $J=16.0$ ), 7.18 (dd, $1 \mathrm{H}$, $\mathrm{H}(15), J=8.5, J=7.3), 7.32$ (d, 2H, H(20), H(24), $J=8.7), 7.44$ $(\mathrm{d}, 1 \mathrm{H}, \mathrm{H}(17), J=16.0), 7.46$ (d, 1H, H(11) $J=8.0), 8.03$ (d, 1H, $\mathrm{H}(14), J=8.6)$, 8.51-8.56 (m, 2H, H(10), H(16)).

(Z)-2-Butyl-6-(4-methoxystyryl)-1H-benzo[d,e]isoquinoline1,3(2H)-dione (Z-NI1). ${ }^{1} \mathrm{H}$ NMR: $0.89\left(\mathrm{t}, 3 \mathrm{H}, \mathrm{CH}_{3}(1), J=7.3\right)$, 1.30-1.37 (m, 2H, $\left.\mathrm{CH}_{2}(2)\right)$, 1.69-1.76 (m, 2H, $\left.\mathrm{CH}_{2}(3)\right), 3.13$ (s, $\left.3 \mathrm{H}, \mathrm{OCH}_{3}\right), 4.20\left(\mathrm{t}, 2 \mathrm{H}, \mathrm{CH}_{2}(4), J=7.9\right), 6.42(\mathrm{~d}, 2 \mathrm{H}, \mathrm{H}(21)$, $\mathrm{H}(23), J=8.7), 6.54$ (d, 1H, H(18), $J=12.3), 6.64$ (d, 1H, H(17), $J=12.3$ ), 6.87 (d, 2H, H(20), H(24), $J=8.7), 7.11$ (dd, $1 \mathrm{H}$, $\mathrm{H}(15), J=7.4, J=8.4), 7.29-7.32(\mathrm{~m}, 1 \mathrm{H}, \mathrm{H}(11)), 8.01$ (dd, $1 \mathrm{H}$, $\mathrm{H}(14), J=8.4, J=1.1), 8.37$ (d, $1 \mathrm{H}, \mathrm{H}(10), J=7.6), 8.50$ (d, $1 \mathrm{H}$, $\mathrm{H}(16), J=7.4)$.

(E)-2-Butyl-6-(3,4-dimethoxystyryl)-1H-benzo[d,e]isoquinoline1,3(2H)-dione (E-NI2). ${ }^{1} \mathrm{H}$ NMR: $0.92\left(\mathrm{t}, 3 \mathrm{H}, \mathrm{CH}_{3}(1), J=7.3\right)$, 1.31-1.46 (m, 2H, $\left.\mathrm{CH}_{2}(2)\right)$, 1.72-1.86 (m, 2H, $\left.\mathrm{CH}_{2}(3)\right), 3.44$ (s, $\left.3 \mathrm{H}, \mathrm{OCH}_{3}\right), 3.54\left(\mathrm{~s}, 3 \mathrm{H}, \mathrm{OCH}_{3}\right), 4.26\left(\mathrm{t}, 2 \mathrm{H}, \mathrm{CH}_{2}(4), J=7.6\right), 6.62$ (d, 1H, H(21), $J=8.3$ ), 6.93-7.13 (m, 3H, H(18), H(20), H(24)), 7.14-7.21 (m, 1H, H(15)), 7.50 (d, 1H, H(11), $J=8.0), 7.51$ (d, 1H, H(17), $J=15.3$ ), 8.08 (d, 1H, H(14), $J=8.6$ ), 8.49-8.59 (m, 2H, H(10), H(16)).

(Z)-2-Butyl-6-(3,4-dimethoxystyryl)-1H-benzo[d,e] isoquinoline1,3(2H)-dione (Z-NI2). ${ }^{1} \mathrm{H}$ NMR: $0.88\left(\mathrm{t}, 3 \mathrm{H}, \mathrm{CH}_{3}(1), J=7.4\right)$, 1.28-1.37 (m, 2H, $\left.\mathrm{CH}_{2}(2)\right), 1.69-1.76\left(\mathrm{~m}, 2 \mathrm{H}, \mathrm{CH}_{2}(3)\right), 3.04$ $\left(\mathrm{s}, 3 \mathrm{H}, \mathrm{OCH}_{3}\right), 3.22\left(\mathrm{~s}, 3 \mathrm{H}, \mathrm{OCH}_{3}\right), 4.20\left(\mathrm{t}, 2 \mathrm{H}, \mathrm{CH}_{2}(4), J=7.4\right)$,
6.24 (d, 1H, H(21), J = 8.4), 6.48 (s, 1H, H(24)), 6.53-6.59 (m, 2H, $\mathrm{H}(18), \mathrm{H}(20)), 6.66$ (d, 1H, H(17), $J=12.3), 7.07-7.13(\mathrm{~m}, 1 \mathrm{H}$, $\mathrm{H}(15)), 7.36$ (d, 1H, H(11), $J=7.6), 8.04$ (d, 1H, H(14), $J=8.4), 8.39$ (d, 1H, H(10), $J=7.6), 8.49$ (d, 1H, H(16), $J=7.4)$.

(E)-2-Butyl-6-(4-(dimethylamino)styryl)-1H-benzo[d,e]isoquinoline-1,3(2H)-dione (E-NI3). ${ }^{1} \mathrm{H}$ NMR: 0.92 (t, 3H, $\mathrm{CH}_{3}(1), J=7.3$ ), 1.35-1.43 (m, 2H, $\left.\mathrm{CH}_{2}(2)\right), 1.76-1.83$ (m, 2H, $\left.\mathrm{CH}_{2}(3)\right), 2.54$ (s, 6H, $\left.\mathrm{N}\left(\mathrm{CH}_{3}\right)_{2}\right), 4.26\left(\mathrm{t}, 2 \mathrm{H}, \mathrm{CH}_{2}(4), J=7.8\right), 6.55$ (d, 2H, H(21), H(23), $J=8.7), 7.11$ (d, $1 \mathrm{H}, \mathrm{H}(18), J=16.0), 7.17$ (dd, $1 \mathrm{H}, \mathrm{H}(15), J=7.3$, $J=8.3), 7.42(\mathrm{~d}, 2 \mathrm{H}, \mathrm{H}(20), \mathrm{H}(24), J=8.7), 7.50$ (d, 1H, H(17), $J=16.0$ ), 7.52 (d, 1H, H(11), $J=7.3$ ), 8.11 (d, 1H, H(14), $J=8.3$ ), 8.52-8.57 (m, 2H, H(10), H(16)).

(Z)-2-Butyl-6-(4-(dimethylamino)styryl)-1H-benzo[d,e]isoquinoline-1,3(2H)-dione (Z-NI3). ${ }^{1} \mathrm{H}$ NMR: $0.89\left(\mathrm{t}, 3 \mathrm{H}, \mathrm{CH}_{3}, J=7.4\right)$, 1.28-1.36 (m, 2H, $\left.\mathrm{CH}_{2}(2)\right), 1.68-1.77$ (m, 2H, $\left.\mathrm{CH}_{2}(3)\right), 2.33$ (s, 6H, $\left.\mathrm{N}\left(\mathrm{CH}_{3}\right)_{2}\right), 4.22\left(\mathrm{t}, 2 \mathrm{H}, \mathrm{CH}_{2}(4), J=7.7\right), 6.18$ (d, 2H, H(21), H(23), $J=8.9), 6.50(\mathrm{~d}, 1 \mathrm{H}, \mathrm{H}(18), J=12.4), 6.72(\mathrm{~d}, 1 \mathrm{H}, \mathrm{H}(17), J=12.4)$, 6.92-6.97 (m, 2H, H(20), H(24)), 7.09-7.13 (m, 1H, H(15)), 7.44-7.48 (m, 1H, H(11)), 8.07-8.14 (m, 1H, H(14)), 8.42 (d, 1H, $\mathrm{H}(10), J=7.7), 8.50$ (dd, $1 \mathrm{H}, \mathrm{H}(16), J=7.4, J=1.0$ ).

\section{Results and discussion}

Steady-state spectroscopic properties

The wavelengths of maximum absorption ( $\left.\lambda_{\text {max }}^{\text {abs }}\right)$ and emission $\left(\lambda_{\max }^{\mathrm{fl}}\right)$, molar absorptivity $\left(\varepsilon_{\lambda}\right)$, fluorescence quantum yields $\left(\varphi^{\mathrm{fl}}\right)$ and Stokes shifts $(\Delta \tilde{\nu})$ of compounds NI1-3 in protic and aprotic organic solvents covering a wide polarity range are listed in Table 1. As an example, Fig. 1 shows the spectra of NI1-3 in ethyl acetate. $\neq$ Comparison of electron density distribution in frontier molecular orbitals (Fig. 2) reveals that the long wavelength absorption can be attributed to an intramolecular charge transfer (ICT) from either the dimethylamino-, mono- or dimethoxystyryl fragment towards the carbonyl groups of the naphthalimide moiety. In accordance with the typical behavior of ICT bands, the increase in electron donating character of the styryl fragment on going from NI1 to NI3 causes the red shift of the absorption and emission maxima (Fig. 1).

Considering the push-pull character of the studied molecules, we proposed that the solvent polarity growth would enhance the ICT in the excited state, which would lead to pronounced changes in the dipole moments upon excitation. Indeed, the absorption maxima showed a slight red shift with increasing solvent polarity, normally interpreted as indicating that the ground state and the Franck-Condon (FC) excited state have similar dipole moments, whereas the fluorescence spectra demonstrated strong solvatochromic effects (Table 1) indicative of a very high relaxed ICT excited state dipole moment as compared to the ground state. In order to demonstrate this hypothesis, we estimated the changes in the dipole moment using the Lippert-Mataga plot, which is essentially a plot of the Stokes shift of the fluorescence emission

† Absorption and fluorescence spectra of NI1 3 in all solvents from Table 1 are listed in the ESI $\dagger$ (Fig. S29 S76). 
Table 1 Absorption and fluorescence characteristics of compounds NI1, NI2, and NI3 in various solvents

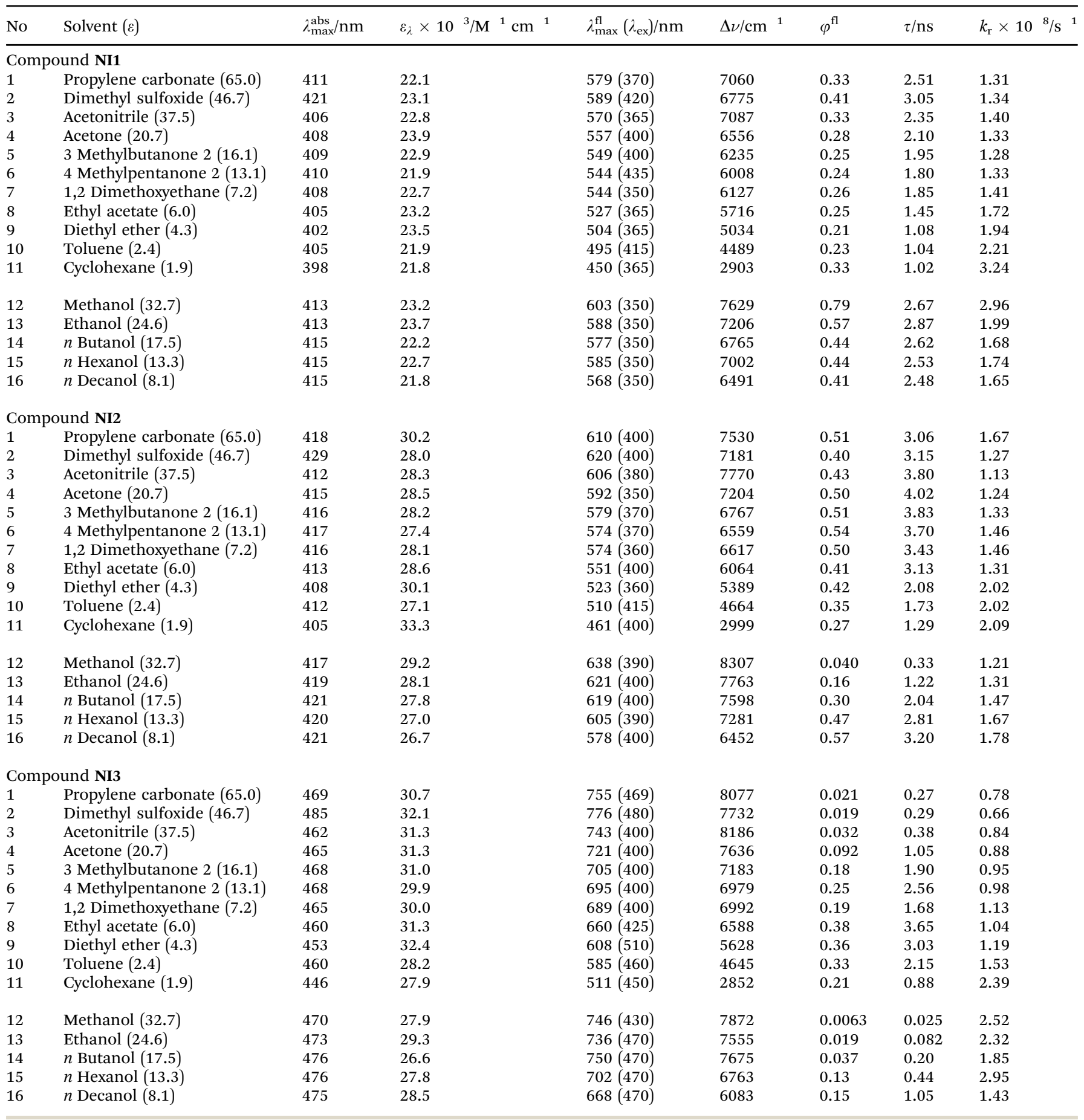

versus the solvent polarity. ${ }^{45,46}$ The equation is expressed as follows:§

$$
\begin{gathered}
\Delta \tilde{\nu}=\tilde{\nu}_{\text {abs }} \quad \tilde{\nu}_{\mathrm{fl}}=\frac{2\left(\mu_{\mathrm{e}}\right.}{\left.h c a_{\mathrm{g}}\right)^{2}}\left[\begin{array}{ccc}
\frac{\varepsilon}{2 \varepsilon+1} & \frac{n^{2}}{2 n^{2}+1}
\end{array}\right]+\text { const } \\
\Delta f=\frac{\varepsilon \quad 1}{2 \varepsilon+1} \quad \frac{n^{2}}{2 n^{2}+1}
\end{gathered}
$$

where $\tilde{\nu}_{\mathrm{abs}}$ and $\tilde{\nu}_{\mathrm{fl}}$ are the wavenumbers of the absorption and fluorescence maxima; $\Delta \tilde{\nu}$ denotes the Stokes shift; $\mu_{\mathrm{g}}$ and $\mu_{\mathrm{e}}$ are the dipole moments of the ground and excited states, respectively; $\varepsilon$ and $n$ are the dielectric constant and the refractive index of the medium, respectively; $h$ is Planck's constant, $c$ is the velocity of light, and $a$ is the radius of the solvent cavity in which the fluorophore resides (Onsager cavity radius). The symbol $\Delta f$ is called the orientation polarizability and accounts for the spectral shifts due to the reorientation of the solvent molecules. 


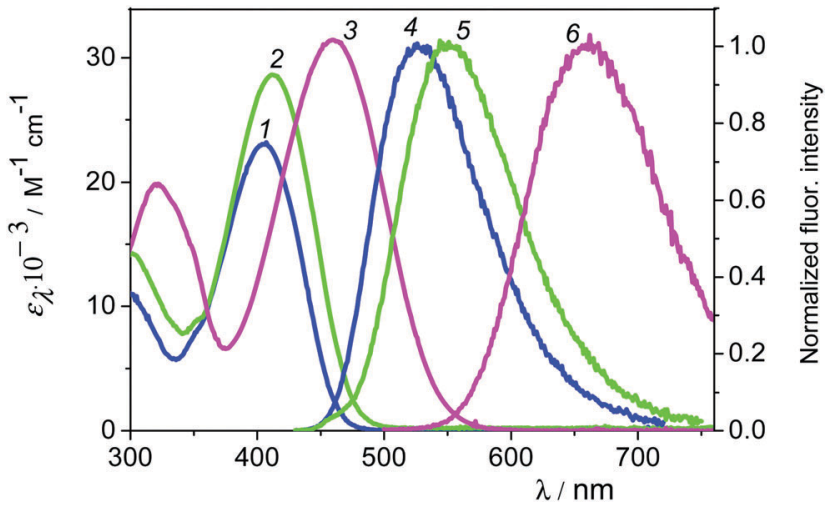

Fig. 1 Absorption (1, 2 and 3) and normalized emission (4, 5 and 6) spectra of compounds NI1 (1 and 4), NI2 (2 and 5) and NI3 (3 and 6) in ethyl acetate.

In general, the reorientation of the solvent molecules is expected to result in substantial Stokes shifts.

The Lippert-Mataga plots of compounds NI1-3 are depicted in Fig. 3. Sixteen solvents were used to explore the change in the dipole moment upon excitation and good linearity was found for the overall regressions with correlation coefficients higher than 0.95. Toluene (no. 10) was not considered in the fitting because correlation with this solvent was poor. Obviously, the interaction between toluene and fluorophore molecules is complex and stands out of the simplified model used in eqn (8) where only non-specific solvation effects are taken into account. Yet, in toluene $(\varepsilon=2.4)$, the emission spectra of all three compounds NI1-3 were structureless, whereas in cyclohexane (a solvent with very close polarity, $\varepsilon=1.9$ ) clear vibronic bands were observed (see Fig. S39b, S55b and S71b in the ESI $\dagger$ ). This result is very close to that obtained in ref. 47 where the photophysical properties of $\mathrm{N}$-alkyl-1,8-naphthalimides in various solvents including alkylated benzenes were studied. The latter were found to form charge transfer complexes in the excited state (exciplexes) upon interaction with the naphthalimide moiety. Probably, the same effect is accountable for the specific solvation in toluene in our case.

Ground state geometry optimization with the PM6 Hamiltonian of MOPAC was used to calculate the farthest distance between the carbonyl oxygen and amino nitrogen or metoxy oxygen of the styryl fragment in molecules NI1-3. Onsager cavity radii of $6.85 \AA$, $6.80 \AA$, and $6.89 \AA$ were obtained as a half of this distance and the dipole moment changes upon excitation estimated from the slopes of linear fit lines in Fig. 1 were found to be around 20.78 D, 21.96 D, and 22.95 D for NI1, NI2, and NI3, respectively. It is known that the value of $4.8 \mathrm{D}$ corresponds to the dipole moment appearing when two unit charges are separated each other by the distance of $1 \AA$. Hence, the changes in the dipole moment of $20.78 \mathrm{D}, 21.96 \mathrm{D}$ and $22.95 \mathrm{D}$ correspond to unit charge separation by $4.33 \AA, 4.58 \AA$ and $4.78 \AA$, which is clear evidence of charge transfer state formation, and also is in a good agreement with the $\left(\mu_{\mathrm{e}} \quad \mu_{\mathrm{g}}\right)$ values obtained for 1,8-naphthalimides with different electron-donating groups at the 4 th position of the naphthalene ring. ${ }^{32,48-52}$

Fluorescence quantum yields of compounds NI1-3 were dramatically influenced by the solvent polarity (Table 1), however, the character of changes was quite complex to be understood only on the basis of the steady-state spectroscopy data. Apparently, to get a deeper insight into the processes occurring after the photoexcitation, time-resolved experiments were strongly needed. So, we further analyzed the effects of the solvent and the molecular structure on the transient absorption (TRABS) spectra.

\section{Transient absorption spectroscopy}

The time-resolved TRABS spectral map of compound NI1 in cyclohexane is shown in Fig. 4a. As it can be seen, the spectral profile of negative signals at $425-500 \mathrm{~nm}$ exhibits a vibronic structure which highly resembles the steady-state fluorescence of NI1 in this solvent (for comparison with the steady-state spectrum see Fig. S77 in the ESI $\dagger$ ). This negative band can be attributed to stimulated emission of the styrylnaphthalimide chromophore from the relatively rigid locally excited (LE) state with mostly planar geometry. The same LE character of the excited states could also be suggested for dimethoxystyryl and dimethylaminostyryl derivatives NI2 and NI3 because in these cases the similar features of negative stimulated emission bands are observed when cyclohexane is used as a solvent (Fig. S83 and S89 in the ESI $\dagger$ ).

Upon the increase of solvent polarity on going from cyclohexane to diethyl ether, a new red-shifted negative band at 575-600 nm emerges in TRABS spectra of all three compounds NI-3 (Fig. 4b-d), indicating the existence of a lower lying
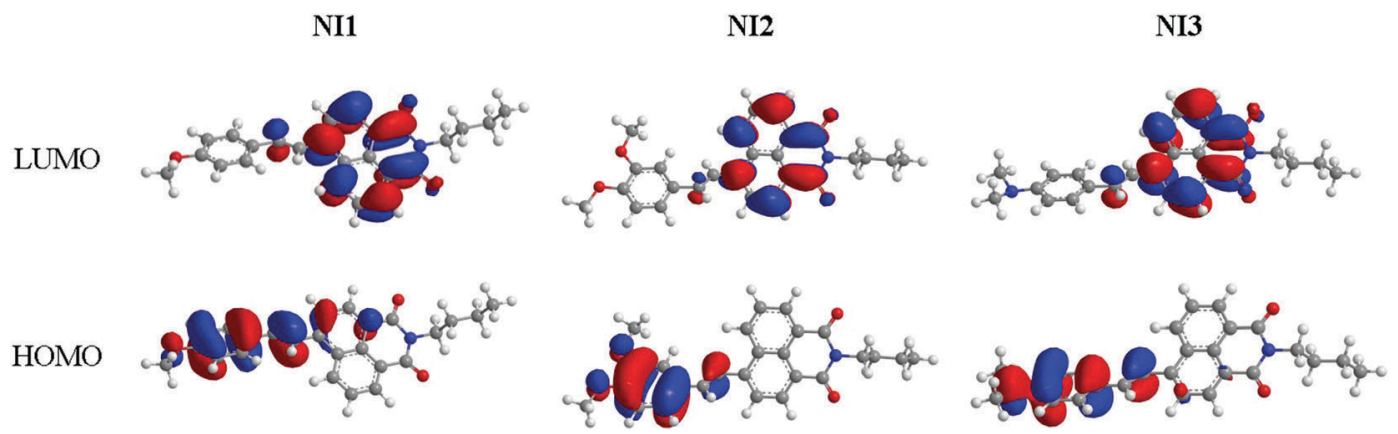

Fig. 2 Frontier orbitals of compounds NI1-3 by the PM6 method 

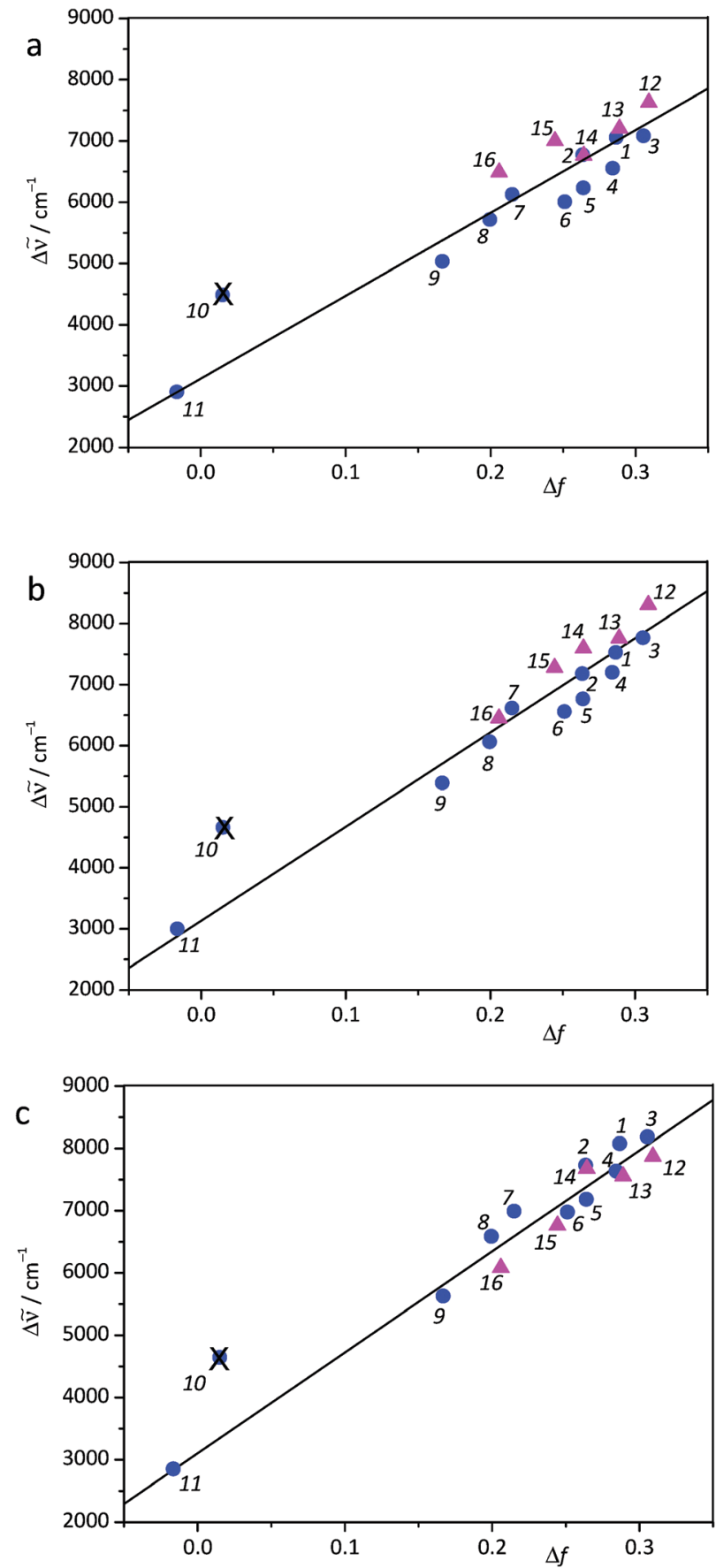

Fig. 3 Dependence of the Stokes shift of NI1 (a), NI2 (b) and NI3 (c) on the solvent polarity function $\Delta f$. The solvents are numbered according to the sequence presented in Table 1. Protic solvents are depicted by triangles and aprotic ones by spots. The straight line represents the best least squares fit to the data (excluding the value obtained for toluene, 10). The correlation coefficients are $0.955,0.974$ and 0.980 for NI1, NI2 and NI3, respectively.

emissive state. Typically to push-pull fluorophores containing a stilbene fragment, an additional deactivation pathway (besides fluorescence, internal conversion and intersystem crossing) of the LE state is open in principle, which involves twisting of one of the single bonds adjacent to the central double bond and leads to a relaxed intramolecular charge transfer state (TICT state) with a higher dipole moment and non-planar geometry. ${ }^{34-36}$ The probability of TICT state formation for the studied styrylnaphthalimides is consistent with the local character of the HOMO and the LUMO of NI1-3 (Fig. 1) as well as it can be clearly seen from the calculated plot of the first singlet excited state $\left(\mathrm{S}_{1}\right)$ energy of compound NI1 versus angle of rotation around the C12-C17 (see Fig. 6 for numbering of atoms) $\sigma$-bond in solvents of different polarities (Fig. 5a). When a non-polar solvent is used $(\varepsilon=1)$ the angle change from 0 to $90^{\circ}$ leads to an increase in energy, whereas in a polar solvent $(\varepsilon=20)$ it reaches maxima at $40^{\circ}$ and then drops rapidly at higher angle values, the effect being understood on the basis of stabilization of the TICT state in a more polar environment.

Generally, one could suggest several ways of formation of the TICT state for the studied compounds NI1-3. Thus, in the case of dimethylaminostyryl derivative NI3 torsion of the molecule may proceed not only around the $\mathrm{C} 12-\mathrm{C} 17$ bond (naphthalimide group twist), but also C18-C19 (phenyl group twist) and N2-C22 (dimethylamino group twist). To speculate on the most probable nature of the TICT state $S_{1}$ state energy calculations for changing the twist angle of the selected bonds (C12-C17; C18-C19 or N2-C22) of NI3 in polar solvent $(\varepsilon=20)$ were carried out. As it can be seen from Fig. 5b, the twist of phenyl in the excited state indicates a possible formation of the TICT state, however, the twist of naphthalimide forms a more energetically favorable TICT state. The twist of the dimethylamino group in the excited state is not energetically favorable and can be excluded from further discussion. Thus, the most probable twisting in the excited state occurs for the naphthalimide fragment as the potential energy of such a twisted state is lower compared with any other one. Moreover, after being placed on the excited state surface, the rotation of naphthalimide decreases only potential energy instead of phenyl, where the state energy during rotation must overcome a potential barrier and hence, such a process is much more time consuming.

The analysis TRABS kinetics showed that the disappearance of the LE state signal in the case of compounds NI1 and NI2 proceeded with almost the same characteristic times $\left(\tau_{2}\right)$ as the appearance of TICT state absorption in various solvents $\left(\tau_{1}\right) \cdot \boldsymbol{\Phi}$ As expected, the increase of solvent polarity resulted in higher rates of formation of TICT states (Table 2). A little difference between $\tau_{1}$ and $\tau_{2}$ can be explained by the fact that the time $\tau_{1}$ is affected to some extent by the dynamic solvation of the twisted form which shifts the TICT absorption band to longer wavelengths on a timescale of the excited state relaxation map. Dynamic solvation effects were very easily detectable when polar solvents with low viscosity (like acetonitrile) were used. The full data on TRABS spectral maps, TRABS spectra at different time delays and time profiles of the signals are presented in the ESI $\dagger$ (Fig. S77-S94).

A very interesting particularity was found in the TRABS spectra of NI1 and NI2 recorded in diethyl ether. In these cases, the residual signals of LE states were not completely quenched

T Time evolution of TRABS signals and fitting kinetic curves at different wavelengths can be found in the ESI. $\dagger$ 

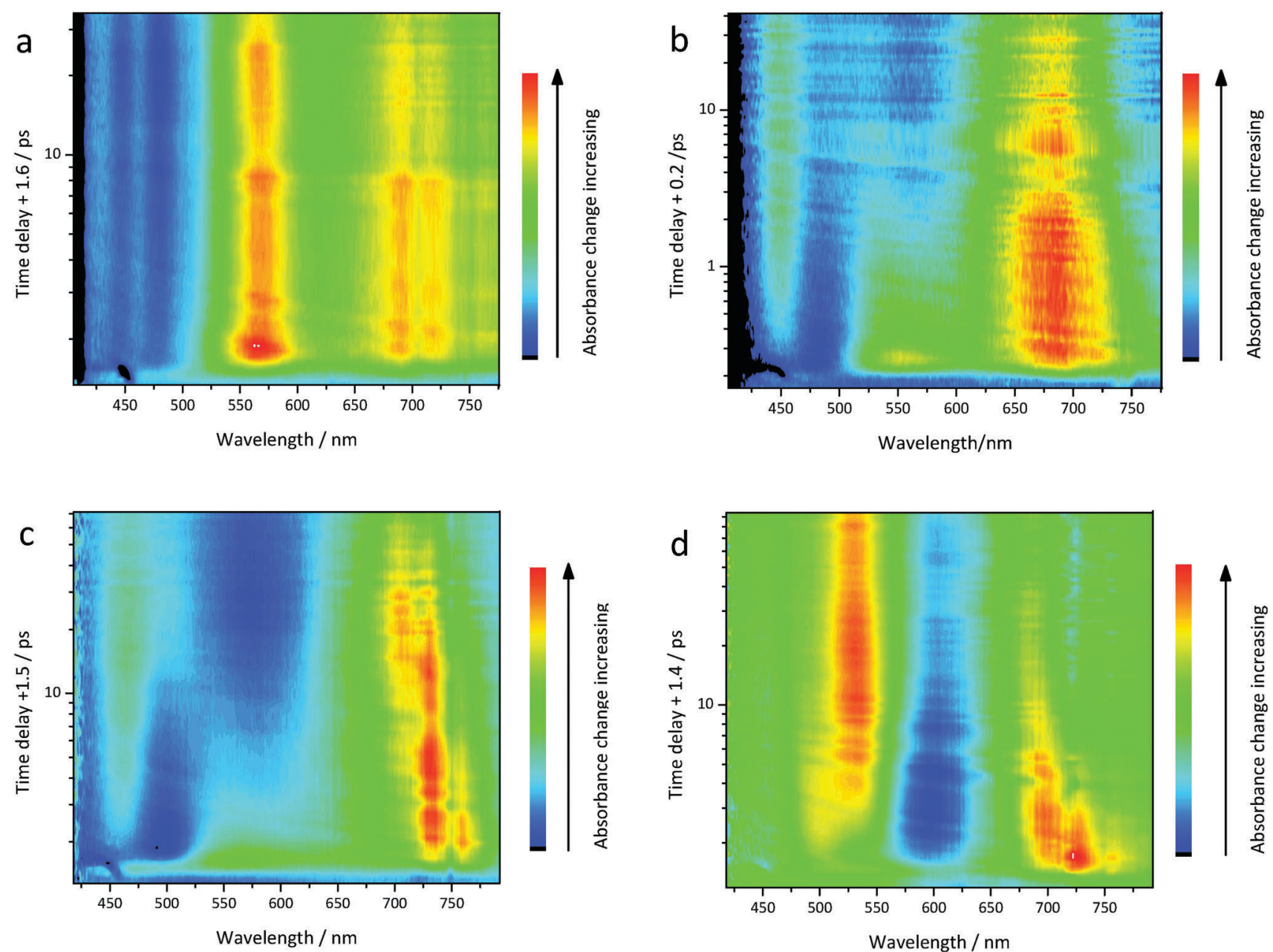

Fig. 4 Time resolved TRABS maps of compounds NI1-3: (a) NI1 in cyclohexane; (b) NI1 in diethyl ether; (c) NI2 in diethyl ether; (d) NI3 in diethyl ether. In order to adjust the best visibility of kinetics of various processes on the logarithmic scale some artificial time delays represented as numbers $+1.6 /+1.5 /+0.2 /+0.4$ are added on the time delay axis legend.

during the lifetime of TICT forms. This observation allows us to conclude that a quasi-equilibrium between twisted and planar forms is possible, which could be a result of a low TICT-LE energy gap due to relatively weak solvation in $\mathrm{Et}_{2} \mathrm{O}$. As the comparison of Fig. $4 \mathrm{~b}$ and $\mathrm{c}$ shows, the fraction of the LE state was reduced for the compound NI2 where the dipole moment and thus, the solvation energy of the excited state are higher with respect to those of NI1. In solvents more polar than diethyl ether, a complete disappearance of LE state absorption signals with $100 \%$ yield of the twisted form was observed (see the ESI $\dagger$ ).

The transient absorption spectrum of compound NI3 in $\mathrm{Et}_{2} \mathrm{O}$ (Fig. 4d) was essentially different from that of NI1 and NI2. In this case, the formation of a planar locally excited state was not observed. The excitation of NI3 directly produced a local excited state with a twisted geometry, as evident from the appearance of the red-shifted negative stimulated emission band of the TICT form at around $600 \mathrm{~nm}$ immediately followed by the excitation pulse. Indeed, the obtained TRABS data are in a very good agreement with the X-ray structures of naphthalimides NI1-3 (Fig. 6), which show that the NI3 molecule in the ground state seems to have some preorganization for rapid yielding of the TICT state as the dihedral angle C11-C12-C17-C18 of compound NI3 is much higher $\left(32.5^{\circ}\right)$ compared with that of NI2 $\left(1.6^{\circ}\right)$ and NI1 $\left(10.8^{\circ}\right)$. It should also be noted that the TICT state in the case of NI3 is more polar, as it can be realized considering the strongest electron donating character of the dimethylaminostyryl fragment. Experimentally, this was expressed in the dynamic solvation of the TICT state, which caused a slight slope of the stimulated emission band at $600 \mathrm{~nm}$ on the TRABS map (Fig. 4d) with a concomitant appearance of a small negative signal at $720 \mathrm{~nm}$. Obviously, both these negative signals correspond to the same TICT state likely possessing a broad emission region, which is partially consumed by the positive signal of excited state absorption.

Thus, in solvents more polar than diethyl ether, the planar LE state transforms effectively into a TICT state with lower energy which further undergoes either fluorescence or non-radiative decay. The existence of two emissive states for NI1-3 has also been revealed by the plots of fluorescence quantum yields versus 


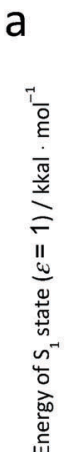
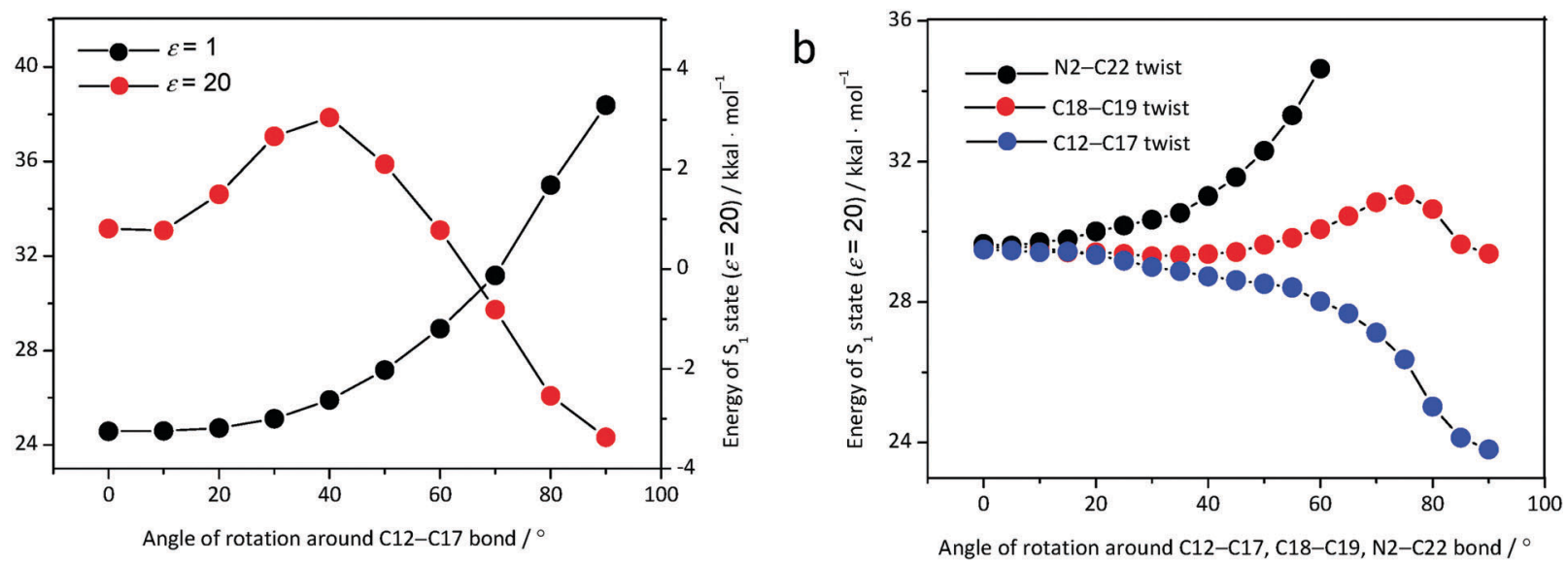

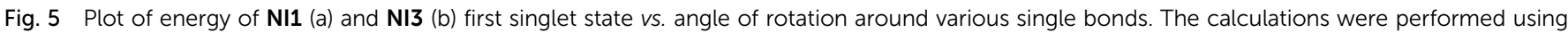
MOPAC 2012.

Table 2 Characteristic times of the disappearance of LE state signals $\left(\tau_{2}\right)$ and the appearance of TICT state signals $\left(\tau_{1}\right)$ in the TRABS spectra of the compounds NI1 and NI2 in different solvents

\begin{tabular}{llllll}
\hline & NI1 & & NI2 & \\
\cline { 2 - 3 } \cline { 5 - 6 } & $\tau_{1} / \mathrm{ps}$ & $\tau_{2} / \mathrm{ps}$ & & $\tau_{1} / \mathrm{ps}$ & $\tau_{2} / \mathrm{ps}$ \\
\hline Diethyl ether & 1.90 & 2.20 & & 2.32 & 2.13 \\
1,2 Dimethoxyethane & 1.23 & 1.46 & & 1.10 & 0.83 \\
Acetonitrile & 0.14 & 0.14 & Not determined $^{a}$ & 0.14
\end{tabular}

${ }^{a}$ The TICT state band is partially consumed by the positive signal of excited state absorption (ESI, Fig. S86).

the excited state lifetime which were constructed from the data on $\varphi^{\text {fl }}$ and $\tau$ in Table 1 (Fig. S95, ESI $\dagger$ ). In these plots, the increase in the excited state lifetime during the solvent change resulted in the increase of the quantum yield, the ratio $\varphi^{\mathrm{fl}} / \tau$ equal to the radiative relaxation rate $\left(k_{\mathrm{r}}\right)$ being kept approximately constant for the majority of aprotic solvents used (Table 1). Accurately, a good linearity was observed for all aprotic solvents except cyclohexane and toluene (also diethyl ether in the case of NI1 and NI2), showing the appearance of another radiative state with a different $k_{\mathrm{r}}$ value.

\section{Photoisomerization studies}

As it was mentioned above, photochemical $E, Z$-isomerization is a distinctive property of styryl dyes and substituted stilbenes which should always be taken into consideration once one tries to speculate about the photophysics of such types of systems. To study photoisomerization the solvents where the nature of the lowest emitting state of NI1-3 is different were chosen. We used cyclohexane and toluene since in these solvents the LE state for all three compounds is dominant in governing the rates of the main relaxation pathways. On the other hand, it was interesting to verify whether $E, Z$-isomerization may occur when the lowest excited state responded for the fluorescence is the TICT state. For this purpose a polar aprotic solvent acetonitrile was used.

Upon irradiation at $436 \mathrm{~nm}$, solutions of NI1-3 in toluene and cyclohexane exhibited a pronounced decrease of the long wavelength absorption band with a simultaneous increase of intensity at shorter wavelengths (Fig. S1-S6, ESI $\dagger$ ), which is typical for the transformation of an $E$ - into $Z$-isomer. However, when irradiation was carried out in acetonitrile, very slight changes in the absorption spectra were observed for all three compounds (Fig. S7-S9, ESI $\dagger$ ). This result allows us to conclude that only planar LE states responded for the E,Z-photoisomerization. Considering the above analysis of TRABS spectra, a suggestion can be made that in all solvents except cyclohexane and toluene (also diethyl ether in the case of NI1 and NI2) where TICT states are dominant, $E, Z$-photoisomerization does not play any significant role in the photophysics of studied compounds.

To confirm the possibility of $E, Z$-isomerization in the excited states ${ }^{1} \mathrm{H}$ NMR spectroscopy was also used. In toluene- $d_{8}$ solutions, compounds NI1-3 exist as thermodynamically stable $E$-isomers showing spin-spin coupling constants of olefinic protons ${ }^{3} J_{\mathrm{H} 18-\mathrm{H} 17}$ equal to $15.3-16.0 \mathrm{~Hz}$. After the irradiation, the signals of the $E$-isomer decreased, whereas a new set of signals with a lower ${ }^{3} J_{\mathrm{H} 18-\mathrm{H} 17}$ constant $(12.3-12.4 \mathrm{~Hz})$ corresponding to the $Z$-isomer was detected. As an example, Fig. 7 shows the ${ }^{1} \mathrm{H}$ NMR spectra of compound NI3 before and after irradiation at $436 \mathrm{~nm}$. The spectra of $E$-isomers and corresponding photostationary states of NI1 and NI3 can be found in the ESI $\dagger$ (Fig. S10).

The spectral characteristics of phototransformation products ( $Z$-isomers) were investigated by the Fisher method ${ }^{39}$ from the absorption spectra of two photostationary states obtained at irradiation wavelengths 436 and $365 \mathrm{~nm}$ and the spectra of $E$-isomers. Also, the quantum yields of the forward $(E \rightarrow Z)$ and backward $(Z \rightarrow E)$ photoreactions were determined. The data are summarized in Table 3. As the values of $\varphi$ is show, isomerizatiom is the main deactivation pathway of LE states of E-NI1-3 in toluene and cyclohexane.

\section{Fluorescence quantum yields and excited state lifetimes}

Aiming to rationalize the effects of solvent polarity on the fluorescence quantum yields and excited state lifetimes in those cases where the emission is originating mostly from the TICT form, we suggested the two factors that should be 
considered in the analysis. The first one is the stabilization of the TICT state due to strong solvation in a more polar medium. This leads to an increase in the lifetime and the emission quantum yield. On the other hand, a higher solvation in polar solvents (especially specific one by hydrogen bonding in water and alcohols) results in the effective transformation of excitation energy into multiple vibrational quanta, i.e. internal conversion to the ground state (the second factor), which in contrast would decrease the values of $\tau$ and $\varphi^{\mathrm{fl}}$.

The opposite spectral effects induced by the two factors were observed for the compounds NI1 and NI3 in aprotic solvents. Methoxystyryl naphthalimide NI1 demonstrated an almost linear increase in $\varphi^{\mathrm{fl}}$ with the increase of $\tau$ when the solvent was changed from ethyl acetate to propylene carbonate (Table 1 and Fig. S95a in the ESI $\dagger$ ), showing that the factor 1 plays the major role. A good linearity for the dependence of $\varphi^{\mathrm{fl}}$ on $\tau$ also took place for NI3, however, in this case the increase in solvent polarity reduced the lifetime and the quantum yield (Table 1 and Fig. S95c in the ESI $\dagger$ ), which could be realized by the priority of the second factor. Thus, one can conclude that the competition between the two factors depends on the charge separation in the excited TICT state. Following this logic, the highest dipole moment of the TICT form of compound NI3 makes it rapidly undergo internal conversion to $\mathrm{S}_{0}$, while a less polar TICT state of NI1 seems to have got a stabilizing effect when the interactions with solvent molecules are increased. In the case of dimethoxystyrylnaphthalimide NI2, where the electron releasing properties of the styryl fragment are higher than those in NI1 but lower than those in NI3, the mean situation occurs that is reflected in the interplay between these two factors. As a result, the fluorescence quantum yield and the excited state lifetime are not influenced dramatically upon the change of the aprotic solvent (Table 1). The similar intermediate case by all appearance could be realized for compound NI1 in protic solvents (Table 1), in which solvation effects are intensified by the hydrogen bonding to such an extent that the leak of the excitation energy through internal conversion becomes favorable. Based on the above analysis, there could be supposed to be three types of spectral behaviors of NI1-3 upon the change in the solvent polarity: (i) factor 1 is dominant (NI1 in aprotic solvents); (ii) both factor 1 and factor 2 respond to the relaxation of the TICT state (NI1 in protic and NI2 in aprotic solvents); (iii) factor 2 is dominant (NI3 in protic and aprotic solvents).

NI1

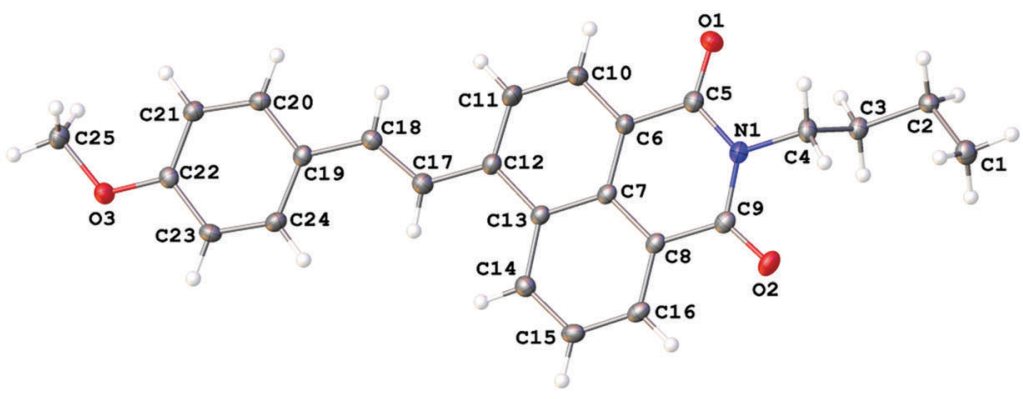

NI2

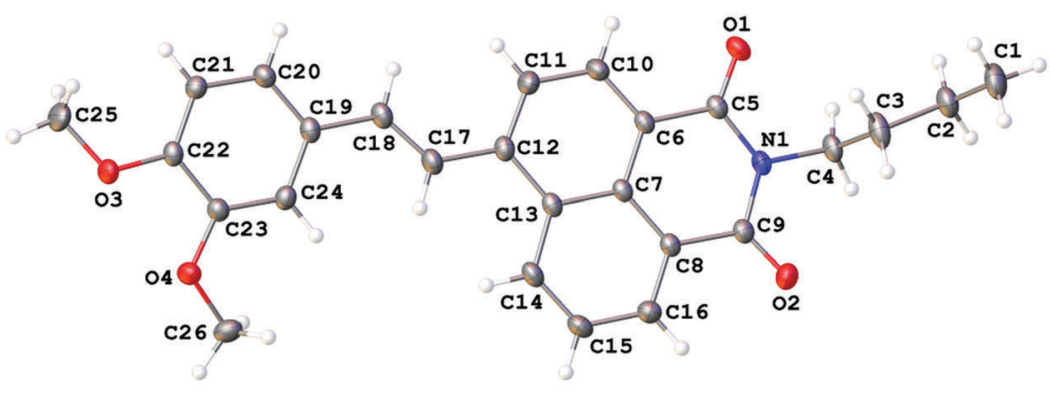

NI3

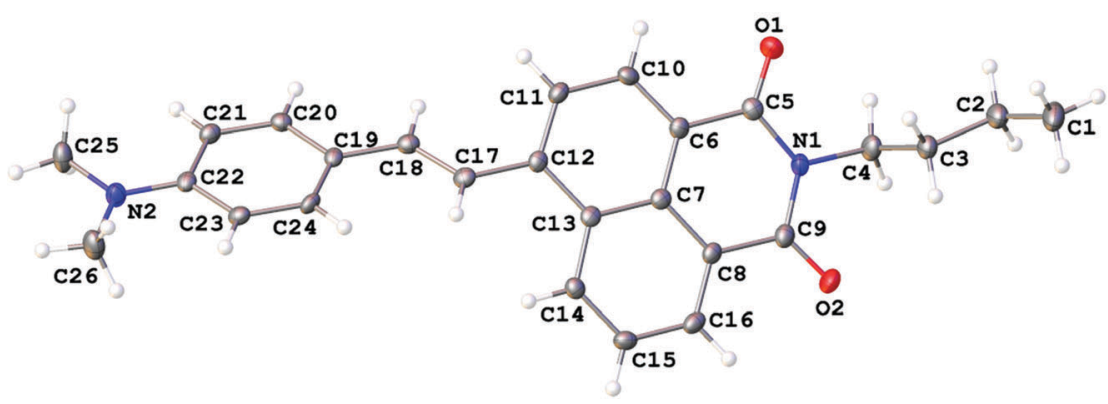

Fig. $6 \times$ ray crystallography data for the compounds NI1-3. 

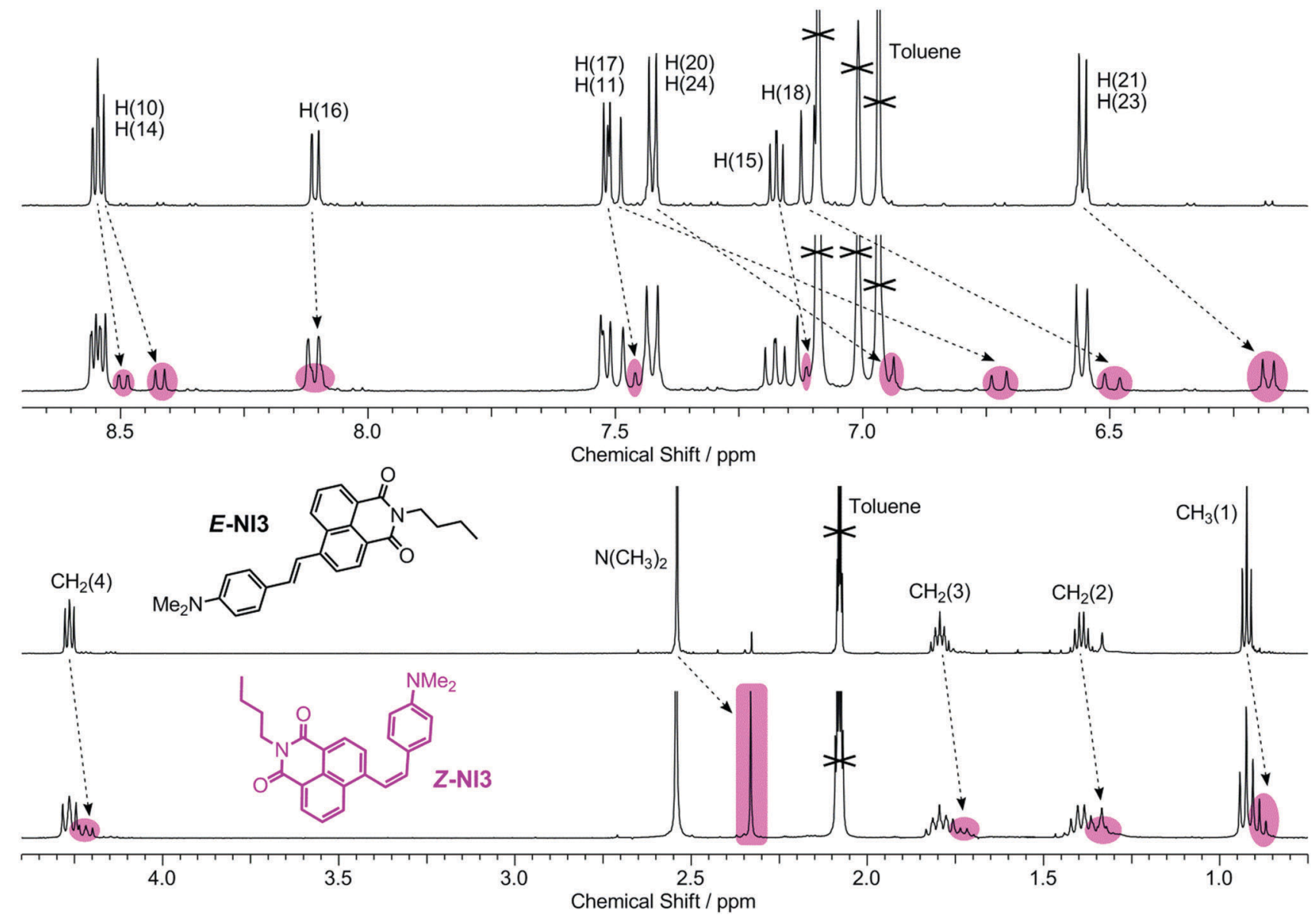

Fig. 7 Aromatic and aliphatic part of the ${ }^{1} \mathrm{H}$ NMR spectrum of compound NI3 in toluene $d_{8}$ before (top) and after (bottom) irradiation at $436 \mathrm{~nm}$. The signals of the $Z$ isomer are marked with color. The concentration of NI3 is $2 \times 10^{2} \mathrm{M}$. The arrows show the upfield shift of proton signals upon photoisomerization. The numbering of atoms is shown in Fig. 6.

Table $3 E, Z$ Photoisomerization quantum yields and spectral characteristics of $E$ and $Z$ isomers of compounds NI1, NI2 and NI3 in toluene and cyclohexane

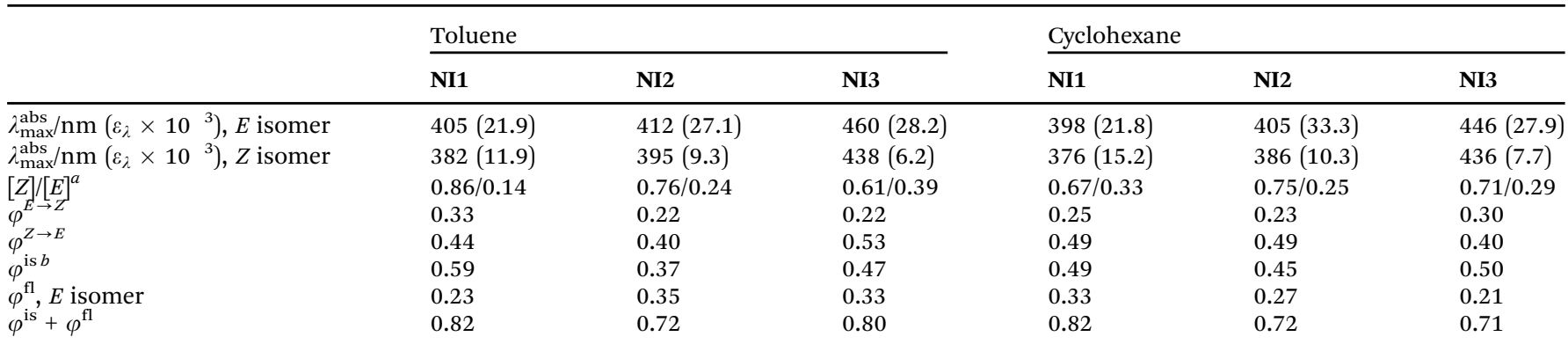

${ }^{a}[Z] /[E]$ is the molar ratio of $Z$ and $E$ isomers in the photostationary state obtained after irradiation at $436 \mathrm{~nm} .{ }^{b}$ Calculated as $\varphi^{\text {is }} \quad \varphi^{E \rightarrow Z} /\left(1 \quad \varphi^{Z \rightarrow E}\right)$. The value $\varphi^{\text {is }}$ corresponds to the fraction of molecules of the $E$ isomer in the initially formed LE state relaxing via the isomerization pathway.

\section{Conclusion}

To conclude, we have shown that the main relaxation pathways of the local excited singlet state of compounds NI1-3 are fluorescence, formation of the TICT state and E,Z-photoisomerization. The interplay between these pathways occurs when either solvent or electron donating properties of the styryl fragment are changed. Isomerization proceeds effectively only in non-polar solvents like cyclohexane and toluene where the planar LE states are dominant. The twisting of the styrylnaphthalimide chromophore is favored by the introduction of an extra methoxy or dimethylamino group into the molecule NI1 as well as by the polar environment. In the solvents ranging from ethyl acetate to methanol the fluorescence emission has mostly a TICT nature and can also be modulated using these two factors. 
As it has been mentioned in the Introduction section, biological applications of NIR dyes as molecular fluorescent probes and markers require them to show several features, the most important being high Stokes shift values, red shifted absorption and emission maxima as well as high emission quantum yield. Very often, dyes exhibiting high values of Stokes shift and NIR fluorescence possess a significant ICT character in the excited state. This means that solvation in polar media like alcohol or water would lead to fluorescence quenching since the internal conversion rate would increase as a result of both the $S_{0}-S_{1}$ energy gap decrease and a great number of possible vibrations in the solvates including multiple solvent molecules. This is a common disadvantage of ICT fluorophores. Our study illustrates that in the case of NI1 and NI2 molecules the TICT states may be stabilized in polar media ensuring rather high fluorescence. It was very unusual to observe long wavelength emission (about $620 \mathrm{~nm}$ ) of NI2 which is a typical ICT system in DMSO or ethanol with a rather high quantum yield of $0.16-0.40$. In contrast to the majority of naphthalimide dyes, the studied compounds NI1-3 have demonstrated a rather high fluorescence originating from TICT states. Indeed, in most of the cases, TICT states of 4-amino-1,8-naphthalimides are not fluorescent or weakly fluorescent, which is a reason commonly used to explain the quenching effect of polar protic solvents on the emission intensity. ${ }^{51-53}$ With this point of view, compounds NI1 and NI2 appear to be very interesting, because their TICT fluorescence remains approximately at the constant level when the polarity of a protic (for NI1) or aprotic (for NI2) solvent increases.

Thus, we have performed a precise analysis of the effects of the solvent and the molecular structure on the photophysics of styrylnaphthalimides. We believe that the results presented herein would be useful for understanding the spectral properties of naphthalimide dyes as well as would help researchers working in the field of life sciences to properly choose fluorophores relevant to satisfy a specific system's requirements.

\section{Acknowledgements}

O. A. F. thanks RSF project No. 16-13-10226 (synthesis of the compounds, X-ray data and photoisomerization studies) and G. J. thanks the Région Aquitaine for financial support (steadystate and time-resolved optical measurements).

\section{References}

1 J. R. Lakowicz, Principles of fluorescent spectroscopy, Springer science + Business Media, LLC, Plenum Publishers, New York, 2006.

2 Z. Foldes-Papp, U. Demel and G. P. Tilz, Int. Immunopharmacol., 2003, 3, 1715-1729.

3 R. Heilker, L. Zemanova, M. J. Valler and G. U. Nienhaus, Curr. Med. Chem., 2005, 12, 2551-2559.

4 H. Mustroph, M. Stollenwerk and V. Bressau, Angew. Chem., Int. Ed., 2006, 45, 2016-2035.
5 K. Rurack, M. Kollmannsberger and J. Daub, Angew. Chem., Int. Ed., 2001, 40, 385-387.

6 Z. Zhang and S. Achilefu, Chem. Commun., 2005, 5887-5889.

7 A. V. Kulinich and A. A. Ishchenko, Russ. Chem. Rev., 2009, 78, 141-164.

8 N. S. James, Y. Chen, P. Joshi, T. Y. Ohulchanskyy, M. Ethirajan, M. Henary, L. Strekowsk and R. K. Pandey, Theranostics, 2013, 3, 692-702.

9 N. S. James, T. Y. Ohulchanskyy, Y. Chen, P. Joshi, X. Zheng, L. N. Goswami and R. K. Pandey, Theranostics, 2013, 3, 703-718.

10 L. G. F. Patrick and A. Whiting, Dyes Pigm., 2002, 52, 137-143.

11 I. Grabchev and R. Betcheva, J. Photochem. Photobiol., A, 2001, 142, 73-78.

12 L. G. F. Patrick and A. Whiting, Dyes Pigm., 2002, 55, 123-132.

13 E. Martin, R. Weigand and A. Pardo, J. Lumin., 1996, 68, 157-164.

14 W. Zhu, M. Hu, R. Yao and H. Tian, J. Photochem. Photobiol., A, 2003, 154, 169-177.

15 G. Tu, Q. Zhou, Y. Cheng, Y. Geng, L. Wang, D. Ma, X. Jing and F. Wang, Synth. Met., 2005, 152, 233-236.

16 C. Coya, R. Blanco, R. Juárez, R. Gómez, R. Martínez, A. de Andrés, Á. L. Álvarez, C. Zaldo, M. M. Ramos, A. de la Peña, C. Seoane and J. L. Segura, Eur. Polym. J., 2010, 46, 1778-1789.

17 L. Song, E. A. Jares-Erijman and T. M. Jovin, J. Photochem. Photobiol., A, 2002, 150, 177-185.

18 X. Meng, W. Zhu, Q. Zhang, Y. Feng, W. Tan and H. Tian, J. Phys. Chem. B, 2008, 112, 15636-15645.

19 O. A. Fedorova, P. A. Panchenko, Y. V. Fedorov, F. G. Erko, J. Berthet and S. Delbaere, J. Photochem. Photobiol., A, 2015, 303-304, 28-35.

20 P. A. Panchenko, O. A. Fedorova and Y. V. Fedorov, Russ. Chem. Rev., 2014, 83, 155-182.

21 R. M. Duke, E. B. Veale, F. M. Pfeffer, P. E. Kruger and T. Gunnlaugsson, Chem. Soc. Rev., 2010, 39, 3936-3953.

22 Z. Xu, J. Yoon and D. R. Spring, Chem. Soc. Rev., 2010, 39, 1996-2006.

23 Z. Xu, X. Qian, J. Cui and R. Zhang, Tetrahedron, 2006, 62, 10117-10122.

24 K. Kawai, K. Kawabata, S. Tojo and T. Majima, Bioorg. Med. Chem. Lett., 2002, 12, 2363-2366.

25 X. Qian, Z. Li and Q. Yang, Bioorg. Med. Chem. Lett., 2007, 15, 6846-6851.

26 M. S. Alexiou, V. Tychopoulos, S. Ghorbanian, J. H. P. Tyman, R. G. Brown and P. I. Brittain, J. Chem. Soc., Perkin Trans. 2, 1990, 837-842.

27 J. L. Magalhães, R. V. Pereira, E. R. Triboni, P. Berci Filho, M. H. Gehlen and F. C. Nart, J. Photochem. Photobiol., A, 2006, 183, 165-170.

28 P. A. Panchenko, Y. V. Fedorov, O. A. Fedorova, V. P. Perevalov and G. Jonusauskas, Russ. Chem. Bull., 2009, 58, 1233-1240.

29 K. Rurack, U. Resch-Genger, J. L. Bricks and M. Spielesa, Chem. Commun., 2000, 2103-2104. 
30 L. Duan, Y. Xu, X. Qian, Y. Zhang and Y. Liu, Tetrahedron Lett., 2009, 50, 22-25.

31 Y. Chen, Y. Wang, Y. Yuan, Y. Jiao, X. Pu and Z. Lu, Phys. Chem. Chem. Phys., 2015, 17, 1309-1316.

32 H.-H. Lin, Y.-Ch. Chan, J.-W. Chen and Ch.-Ch. Chang, J. Mater. Chem., 2011, 21, 3170-3177.

33 S. Luo, J. Lin, J. Zhou, Y. Wang, X. Liu, Y. Huang, Z. Lu and C. Hu, J. Mater. Chem. C, 2015, 3, 5259-5267.

34 V. Papper and G. I. Likhtenshtein, J. Photochem. Photobiol., A, 2001, 140, 39-52.

35 H. El-Gezawy, W. Rettig and R. Lapouyade, J. Phys. Chem. A, 2006, 110, 67-75.

36 E. Benassi, B. Carlotti, M. Segado, A. Cesaretti, A. Spalletti, F. Elisei and V. Barone, J. Phys. Chem. B, 2015, 119, 6035-6040.

37 S. Nad, M. Kumbhakar and H. Pal, J. Phys. Chem. A, 2003, 107, 4808-4816.

38 C. L. Renschler and L. A. Harrah, Anal. Chem., 1983, 55, 798-800.

39 E. Fisher, J. Phys. Chem., 1967, 71, 3704-3706.

40 F. Daniels and R. Alberty, Physical Chemistry, John Wiley and sons, New York, 1975.

41 C. A. Parker, Photoluminescence of Solutions, Elsevier, Amsterdam, 1968.
42 S. Goldstein and J. Rabani, J. Photochem. Photobiol., A, 2008, 193, 50-55.

43 G. M. Sheldrick, Acta Crystallogr., Sect. A: Found. Crystallogr., 2008, 64, 112-122.

44 J. J. P. Stewart, J. Mol. Model., 2007, 13, 1173-1213.

45 E. Lippert, Z. Elektrochem., 1957, 61, 962-975.

46 N. Mataga, Y. Kaifu and M. Koizumi, Bull. Chem. Soc. Jpn., 1956, 29, 465-470.

47 D. W. Cho, M. Fujitsuka, U. C. Yoon and T. Majima, J. Photochem. Photobiol., A, 2007, 190, 101-109.

48 G. J.-F. Demets, E. R. Triboni, E. B. Alvarez, G. M. Arantes, P. B. Filho and M. J. Politi, Spectrochim. Acta, Part A, 2006, 63, 220-226.

49 S. Saha and A. Samanta, J. Phys. Chem. A, 2002, 106, 4763-4771.

50 Z. Li, Q. Yang, R. Chang, G. Ma, M. Chen and W. Zhang, Dyes Pigm., 2011, 88, 307-314.

51 S. L. Dmitruk, S. I. Druzhinin, R. A. Minakova, A. I. Bedrik and B. M. Uzhinov, Russ. Chem. Bull., 1997, 46, 2027-2031.

52 Y. A. Mednykh, Y. A. Manaev, V. V. Volchkov and B. M. Uzhinov, Russ. J. Gen. Chem., 2004, 74, 1728-1733.

53 F. Cosnard and V. Wintgens, Tetrahedron Lett., 1998, 39, 2751-2754. 